\title{
Compositional Design Based on Stochastic Procedures
}

\section{Planejamento Composicional a Partir de Procedimentos Estocásticos}

\section{Liduino Pitombeira}

Universidade Federal do Rio de Janeiro

pitombeira@musica.ufrj.br

\section{Raphael Santos}

mail@raphaelss.com

\begin{abstract}
In this article, we discuss the application of stochastic music techniques in an aesthetic context different from that originally employed by Xenakis. These techniques applied in the serialism of pitch-classes were the basis for the creation of a computer program with the purpose to determine the duration and the harmonic profiles of precompositional materials from restrictions set by the composer. The resulting data, obtained by the exponential probability distribution, allowed us to plan and compose two works: one for pierrot ensemble and other for string quartet.
\end{abstract}

Keyw ords: Composition; Stochastic Music; Xenakis; Probability Distributions.

Resumo: Neste artigo, discutimos a aplicação de técnicas de música estocástica em um contexto estético diferente do originalmente empregado por Xenakis. Estas técnicas aplicadas no serialismo de classes de altura foram a base para a criação de um aplicativo computacional com o objetivo de determinar a duração e os perfis harmônicos de materiais pré-com postos a partir de restrições estabelecidas pelo compositor. Os dados resultantes, obtidos pela distribuição de probabilidade exponencial, nos permitiram planejar e com por duas obras: uma para formação pierrot e outra para quarteto de cordas.

Palavras-chave: composição; música estocástica; Xenakis; distribuições de probabilidade. 


\section{1 - Introduction}

Xenakis, referring to the ultra-deterministic serialism (of Babbitt, for example), states that "the linear polyphony is destroyed by its own complexity; what you hear is just a mass of notes in multiple registers" (Xenakis, 1999, p.41). In other words, the great complexity prevents the perception of individual lines by the listener and the series is "lost".

For Xenakis, there is a contradiction between the inherently linear and polyphonic serial system and what we hear, that is, melodic lines are projected, but the hearing result is, in fact, vertical aggregates, which brings the resulting sonority closer to that of a sound mass than to that of a polyphony. Stochastic music, then, emerged as a means to work at a higher level of abstraction and perform a direct statistical control of sound masses arising from the superposition of layers. Thus, one would avoid linear thinking as a method to generate sound mass. Stochastic music allows a composer to work closer to the sound result and think in terms of macro transformations instead of working with sound mass indirectly, as it happens in linear thinking.

This phenomenon is also criticized by Ligeti, who claimed that even when applied to a single parameter such as pitch, the overlapping and interlacement of the series, typical of serialism, tended to distance the sound results from the original features of the series and that when this procedure is further expanded to other parameters, the emerging complexity causes the series to lose its function completely. In addition, the composer saw as problematic the organization of all musical parameters from a single planning, according to the serial practice, and realized that there was no guarantee that a single order would produce similar structures at various levels of perception. Thus, according to Ligeti, this practice would have led to the reduction of interval sensitivity, therefore favoring structures developed primarily by density relations and disposition of pitch registers and not by its interval content (usually chromatically homogeneous). ${ }^{1}$ Nevertheless, the disciplined use of the series, even in its various versions and possible overlaps can ensure a statistical control of the appearance of all pitchclasses.

According to Xenakis, stochastic music, and even the use of probabilistic and sweepstakes operations, is not an abdication of control by the composer. On the contrary, to work on a higher level of abstraction, that is, closer to the sound result, allows more direct control over how the work will be perceived - as

\footnotetext{
${ }^{1}$ As Jonathan Bernard says: "These observations seem to have brought Ligeti to a key realization: if the qualities he had noted were in fact the true determinants of aural shape in new music, why not engage them directly, instead of through compositional methods that could not control such qualities, except more or less serendipitously?" (Bernard, 1987, p.208-209).
} 
opposed to indirect operations imposed by the linear perspective in a work which main focus is sound mass.

Hence the criticism of the indeterminism used by John Cage and the composers who surrounded him (Morton Feldman, Earle Brown, and Christian Wolff). Xenakis sees the indeterminism during the performance as simply the practice of improvisation, which for him is in itself nothing-innovative (Xenakis, 1994, p.180-181). Compositional indeterminacy, which involves random factors during the composition of a work, despite the apparent proximity to the stochastic music of Xenakis, is also criticized by this composer. The reason is precisely the divergence on the use of randomness. If Xenakis sees the use of stochastic methods as a way to a more comprehensive control, by allowing a composer to use statistics for low-level decisions so he or she can focus on a macro level (thus working from a more abstract point of view), Cage uses randomness as a way to relinquish control and withdraw himself from the composition.

According to Xenakis (1994, p.22-23), an acoustic event may be represented by a vector. A simplified example provided by the composer himself would be a tridimensional vector, $E=(h, g, u)$, where $h$ is the pitch of the sound event, $g$ its intensity, and $u$ its duration. It is noticed that several vectors as this one can be collected and operations on them can be defined, but there is, in principle, no temporal structure involved that specifies their distribution in time. The duration is one of the components of the vector but not the starting point of the event. In other words, these sound events are independent of any temporal structure - they are out of time structures. A set of them does not give us any information about how they are or may be distributed in time. A musical scale, for example, suggests possible structuring out of time, since it does not bring any temporal structural consideration. For Xenakis, there must be this conceptual distinction. One criticism of Xenakis to serialism is precisely the mix of these two categories, as the series already contains in itself an order.

If we have a set of time points, i.e., a temporal structure and map this set to a number of out of time structures, we have now pairs of the form $(t, E)$, where $t$ is a point in time, and $E$ is a vector representing a sound event. These pairs are structures in time. A composition may, therefore, be modeled as a function $f(x)$ of a set of time points (temporal structure) to a set of sound events (out of time structures). Take, for example, the set of atemporal events shown in Figure 1 with no particular order (the numbers on top are used only as identifiers and will be employed in the mapping procedure shown in Figure 2). Each one of these events include specification for pitch, duration, and dynamics. Some of these events are simple (with a single pitch), others compound (having more than one pitch). A certain function $f(x)$ maps one set of points in time to each of these events giving them an attack-point, that is, a position in time. The graph shown in Figure 2 
describes the functional mapping operation that produces the ordered pair $(t, E)$. These pairs are temporal structures and together constitute the realization of the composition itself, which, in this case, produces the initial gestures of Webern's Op. 27 shown in Figure 3.

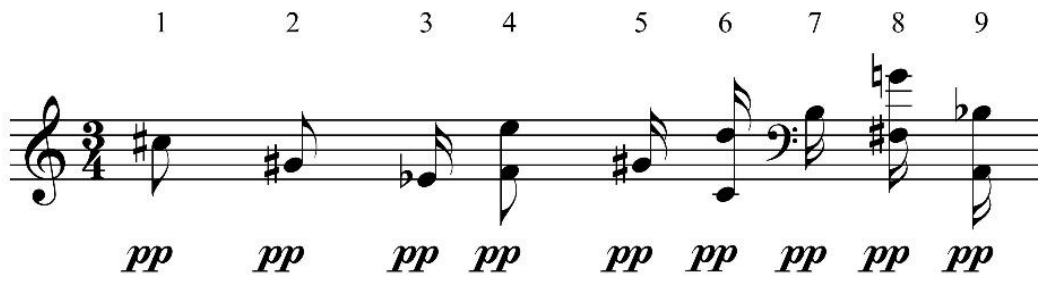

Figure 1: Set of atemporal sound events.

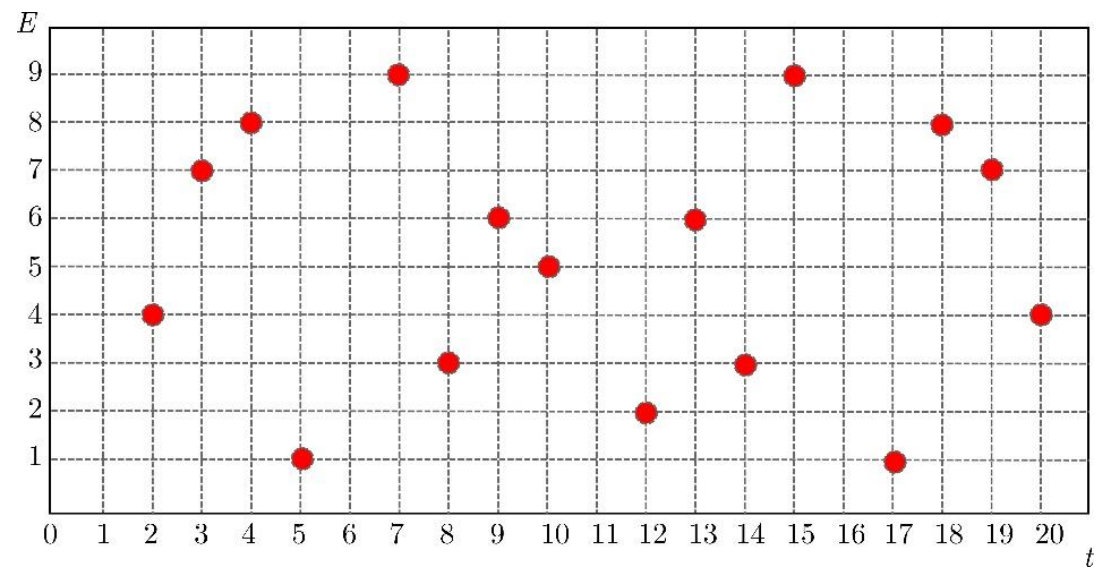

Figure 2: Mapping of $t$ on $E$.

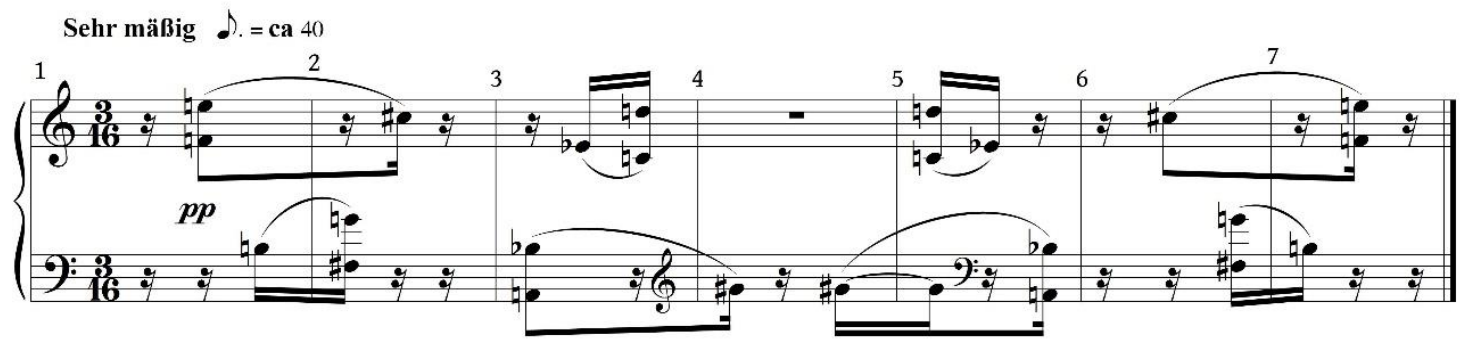

Figure 3: Musical result of the mapping: Webern, Op.27.

Xenakis points out Achorripsis, from 1956-7, his third work using his concepts of stochastic music (Rossetti, 2010, p.3), as a work that follows the principle of minimum compositional restrictions. It arises from the composer's question "What is the minimum of logical constraints necessary for the 
construction of a musical process?" (Xenakis, 1992, p.16). Later, Xenakis would use this same model in his composition with computers, of which the first result was the work ST/10-1,080262. The composer also states that, from this model, (the formal archetype from which Achorripsis arises and that was used as the basis for the algorithm which culminates in ST/10-1,080262, wherein the basic objective is to achieve the highest possible asymmetry, namely the minimum of causality and rules) one would be able to gradually introduce restrictions through choices and denials, which means, in fact, the introduction of compositional decisions.

In this paper, we describe the construction of two works: Oito Momentos para Pierrot Ensemble, by Raphael Santos, and Plate One Nix, for string quartet, by Liduino Pitombeira, using techniques of stochastic music, without, however, a concern in joining the xenakian aesthetic. In the next section, we describe how we abstracted some compositional procedures from Xenakis planning, to form a body of tools we call stochastic technique. We then use these tools in the compositional planning of Oito Momentos para Pierrot Ensemble and Plate One Nix.

\section{2 - Stochastic Technique}

Although stochastic music has arisen in a context related to sound masses, its main contribution is the event control in a probabilistic manner. Therefore, while in music that focus in the production of sound masses, a composer is concerned with densities of sound clouds, and through probabilistic functions abstracts him or herself from the individual details of each sound event, we propose that the abstraction of parameters through probabilistic functions can be employed in other aesthetic fields besides the aesthetic of sound masses. It is worth noting in advance, that we do not propose here an algorithmic approach, but rather the integration of the stochastic technique to the repertoire of techniques already available to the contemporary composer.

At the core of the use of stochastic procedures in composition are the probability distributions. They describe the probability of all possible values of an experiment and, roughly, the analysis of the function associated with the probability distribution of a specific random experiment may provide an intuition on the behavior of this experiment. Xenakis (1992, p.12-16) describes his use of various different distributions associated to several parameters in Achorripsis. We will take as an example the exponential distribution (whose curve is shown in Figure 4), used by the composer to calculate the duration of the events in each sound cloud in this work. In Achorripsis, pitch and all the other event parameters are calculated according to other distributions. However, we propose that these stochastic procedures need not to be used in a monolithic fashion and, like other compositional techniques, can be applied to different contexts and 
associated with many other features. Figure 5 presents a piece of music with rhythms drawn from an exponential distribution and having its pitches derived from the twelve-tone series of Stockhausen's Gruppen. ${ }^{2}$

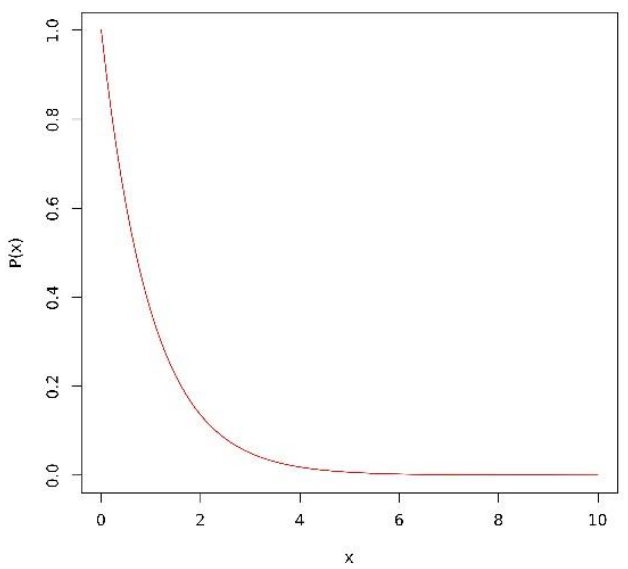

Figure 4: Exponential distribution

Note in the graph of the probability density function for the exponential distribution of Figure 4 that the probability $P(x)$ of a value $(x)$ to occur decreases as this value increases. This behavior is noticeable in the passage of Figure 5, in which shorter rhythmic figures, in fact, predominate. This intuition about distributions behavior and their parameters can be developed without the need for an advanced mathematical basis. Moreover, the possibility of automating these operations through computer application makes the use of these techniques accessible to composers without considerable mathematical fluency.
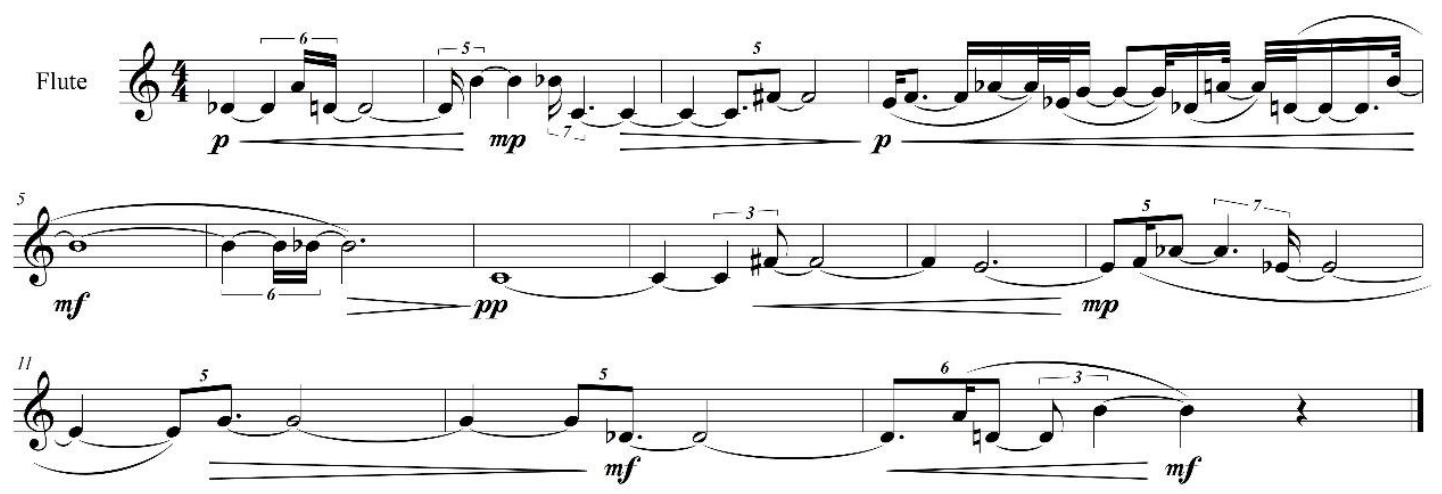

Figure 5: Rhythms drawn from an exponential distribution and pitches derived from the twelve-tone series of Stockhausen's Gruppen.

2 The rhythmic values result from quantizations of real numbers since the distribution is continuous. 
Another example of application of a probabilistic distribution and a more effective option compared to the manual determination of values may be observed in the production of a diffuse periodicity used by Grisey in Périodes, which consists of "periodic events which fluctuate slightly around a constant" (GRISEY, 1987, p.245). Thus, in the example of Figure 6, we have a representation of an absolute periodic event that is completely relaxed by slightly fluctuating around a constant value (4). If the number of events is very large, it is more advantageous to randomly select the individual values through a probability distribution, such as the Gaussian, instead of determining them manually. This distribution, whose curve is shown in Figure 7, has a mean value and a standard deviation. The values around the average value are more likely to occur, and the standard deviation controls the decay curve. Thus, in the example of Figure 6, the values that differ from the constant value are within the scope predicted by the deviation. These values are quantized in order to be represented in traditional musical notation.

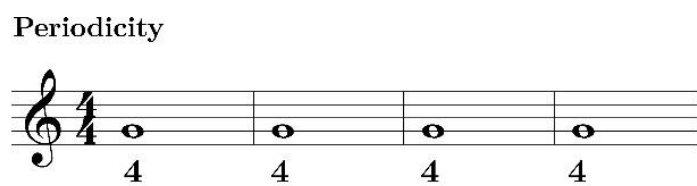

Diffuse Periodicity

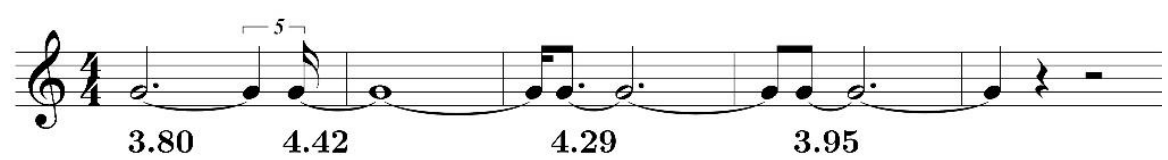

Figure 6: Diffuse periodicity determined by a Gaussian distribution.

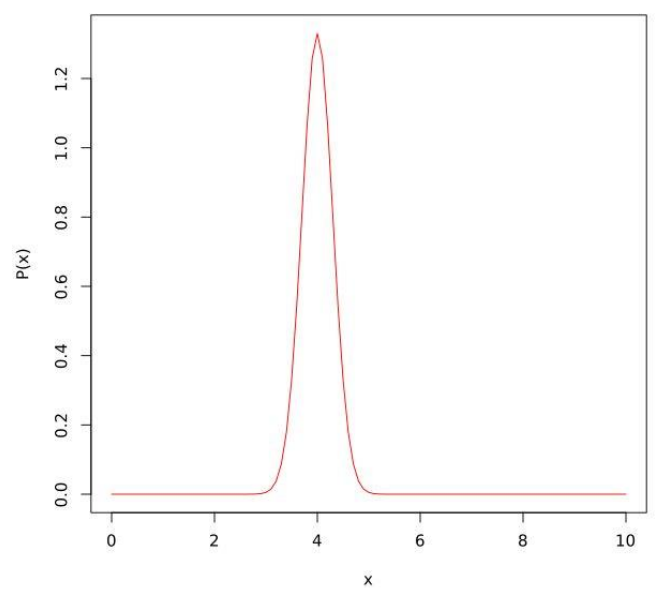

Figure 7: Gaussian distribution with average value 4 and standard deviation 0.3 . 
Due to the customary association between integers and parameters such as pitch, dynamics, duration and onsets in serial composition, discrete distributions may provide a rich source of materials to be used along with the techniques associated with the serial tradition. If we take the geometric distribution (whose curve is shown on Figure 8), commonly seen as the discrete counterpart of the exponential distribution presented above, and use it to generate a stream of numbers, we can interpret these numbers as durations by multiplying them by a given base rhythmic figure as it is usually done in serial composition. In Figure 9, we have an example of such a stream of numbers generated with a geometric distribution with a probability of success of 0.4 and its corresponding rhythm using the sixteenth note as a base duration. For this example, we also used the twelve-tone series of Stockhausen's Gruppen.

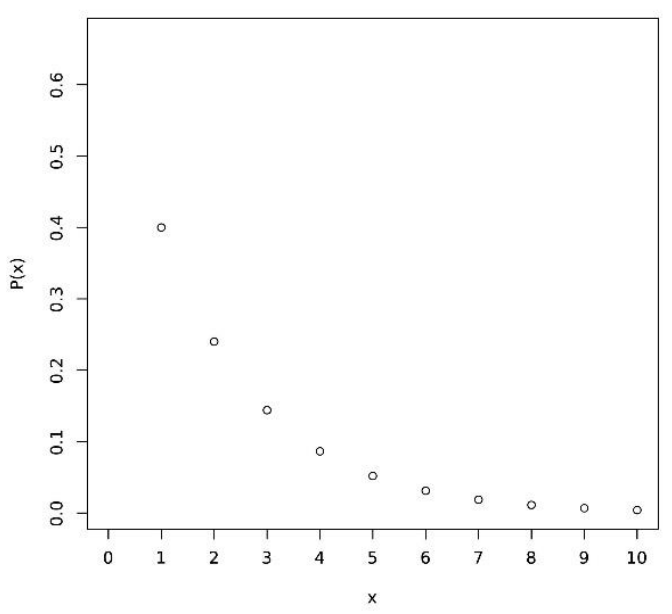

Figure 8: Geometric distribution with probability of success 0.4 .
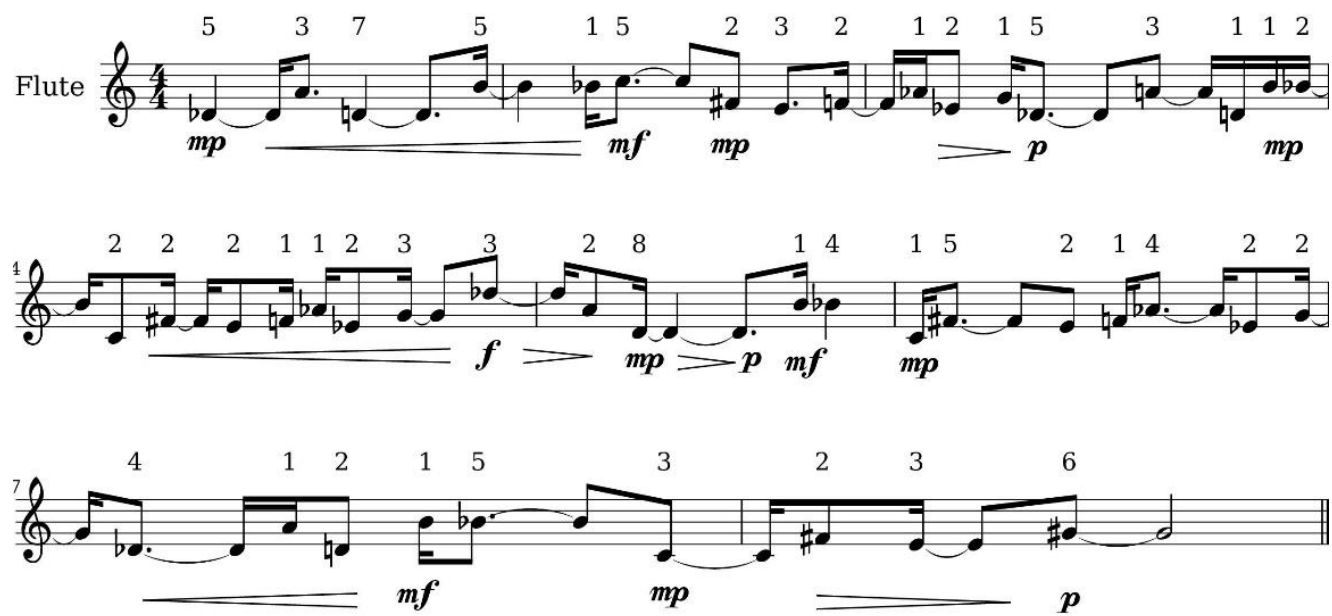

Figure 9: Rhythms drawn from a geometric distribution and pitches derived from the twelve-tone series of Stockhausen's Gruppen. 
From these examples, we can see that any suitable discrete distribution may be easily used in the context of more traditional serial techniques. With a pseudorandom number generator coupled with a set of parameterized distributions abstracted by a computer program and a developed intuition to understand the behavior of the different distributions, a composer can apply them in his/her work without considerable difficulty.

\section{3 - Compositional Planning of Oito Momentos para Pierrot Ensemble}

The system used in the compositional planning of Oito Momentos para Pierrot Ensemble was implemented computationally in C++. The system incorporates stochastic techniques to serial manipulations and produces as a result a number of sections and internal events, which are associated with harmonic regions extracted from a twelve-tone series. The system's flow chart is shown in Figure 10.

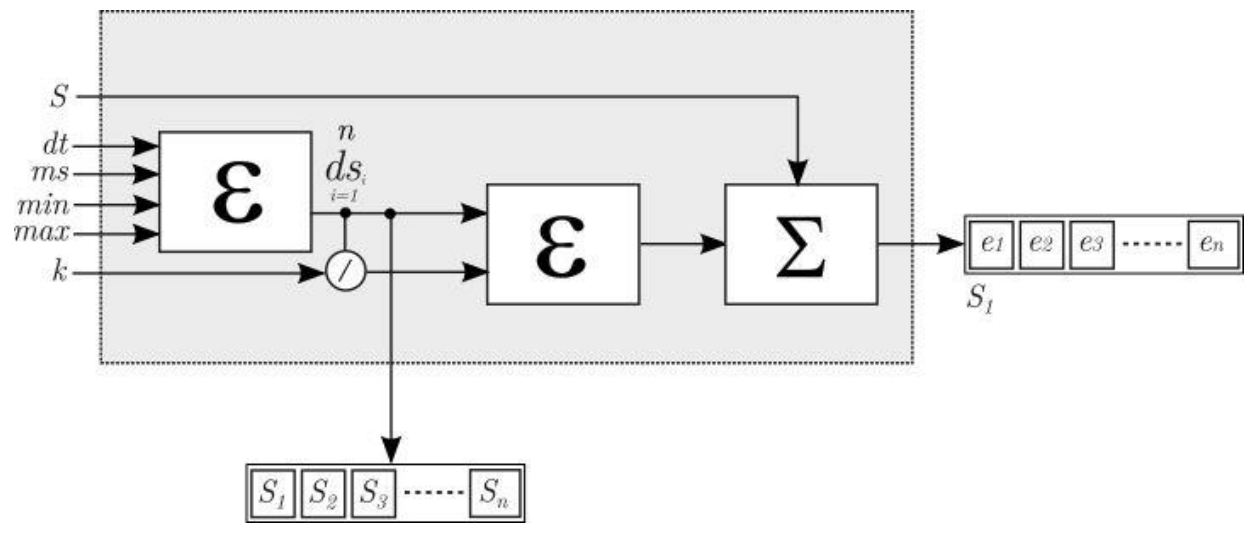

Figure 10: Flowchart of the compositional system.

The composer enters the following data: 1) total duration of the work $(d t)$, 2 ) average length of a section (ms), 3) maximum number of pitch-classes (max), 4) minimum number of pitch-classes ( $\min$ ) 5) average number of events per section $(k)$ and 6) twelve-tone series $(S)$. Initially the system produces the set of sections whose durations are randomly established according to an exponential distribution $\left(P(x)=\lambda e^{-\lambda x}\right)$, in which $\lambda$ corresponds to $m s$. The system provides enough sections to fill out the total duration $(d t)$. This same operation is applied on inner levels to distribute the events within each section. In this case, the total length to be considered is the length of each section and the mean value is the ratio of the number of events per section and the length of the section itself. These 
two steps are applied in blocks designated by the letter $\varepsilon$ in the diagram of Figure 8. Each event is associated with a set of pitch-classes derived from the twelvetone series $(S)$ supplied into the system input. For each event, it is selected a number randomly selected from the min and max values established by the composer. This will determine the number of pitch-classes for this event. When the series is exhausted, another transformation (inversion, retrograde, ...), chosen randomly, is used. These last two random operations are performed from a uniform distribution, that is, all possibilities have an equal chance of occurrence.

For the planning of Oito Momentos para Pierrot Ensemble, the system was fed with the following values: 1) $d t=6$ minutes, 2) $m s=50$ seconds, 3) $\max =6,4$ ) $\min =1,5) k=10$, and 6) the twelve-tone series used $(11,10,2,3,6,7,8,4,5,0,1,9)$ was extracted from the Concerto for Nine Instruments, Op. 24, by Webern. Table 1 shows the eight sections of the work with their respective durations in seconds; and Table 2 shows the events and the durations for the first section. Section 1 of the work is shown in musical notation in Figure 11.

Table 1: Duration of the eight sections of Oito Momentos para Pierrot Ensemble.

\begin{tabular}{|c|c|}
\hline \multicolumn{2}{|c|}{ Section Duration(s) } \\
\hline 1 & 29.7 \\
\hline 2 & 52.1 \\
\hline 3 & 34.7 \\
\hline 4 & 16.5 \\
\hline 5 & 58.6 \\
\hline 6 & 52.8 \\
\hline 7 & 83.6 \\
\hline 8 & 68.6 \\
\hline
\end{tabular}

Table 2: Events and their durations for the first section of Oito Momentos para Pierrot Ensemble.

\begin{tabular}{cc}
\hline \hline Event & Duration(s) \\
\hline B, Bb, D, Eb & 2.18 \\
Gb, G, Ab, E, F & 1.28 \\
C, Db, A & 2.42 \\
Ab, G & 3.16 \\
B, C & 0.0933 \\
Eb, E, F, Db, D & 7.04 \\
A, Bb & 1.75 \\
Gb, D), F, E, A, Ab & 5.01 \\
C & 0.958 \\
B,B $b$ & 4.77 \\
G, Gb,D,Eb & 4.91 \\
\hline \hline
\end{tabular}

\section{MUSICA THEORICA}




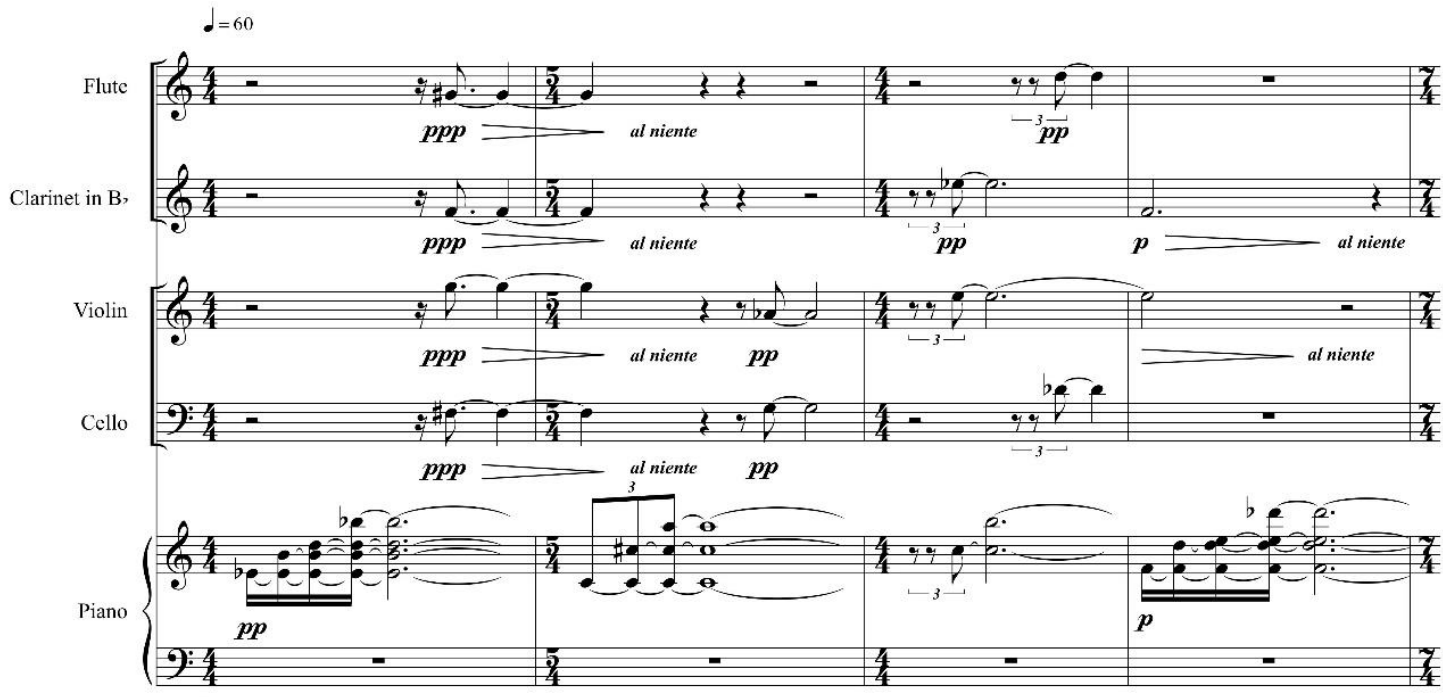

Teor. sempre

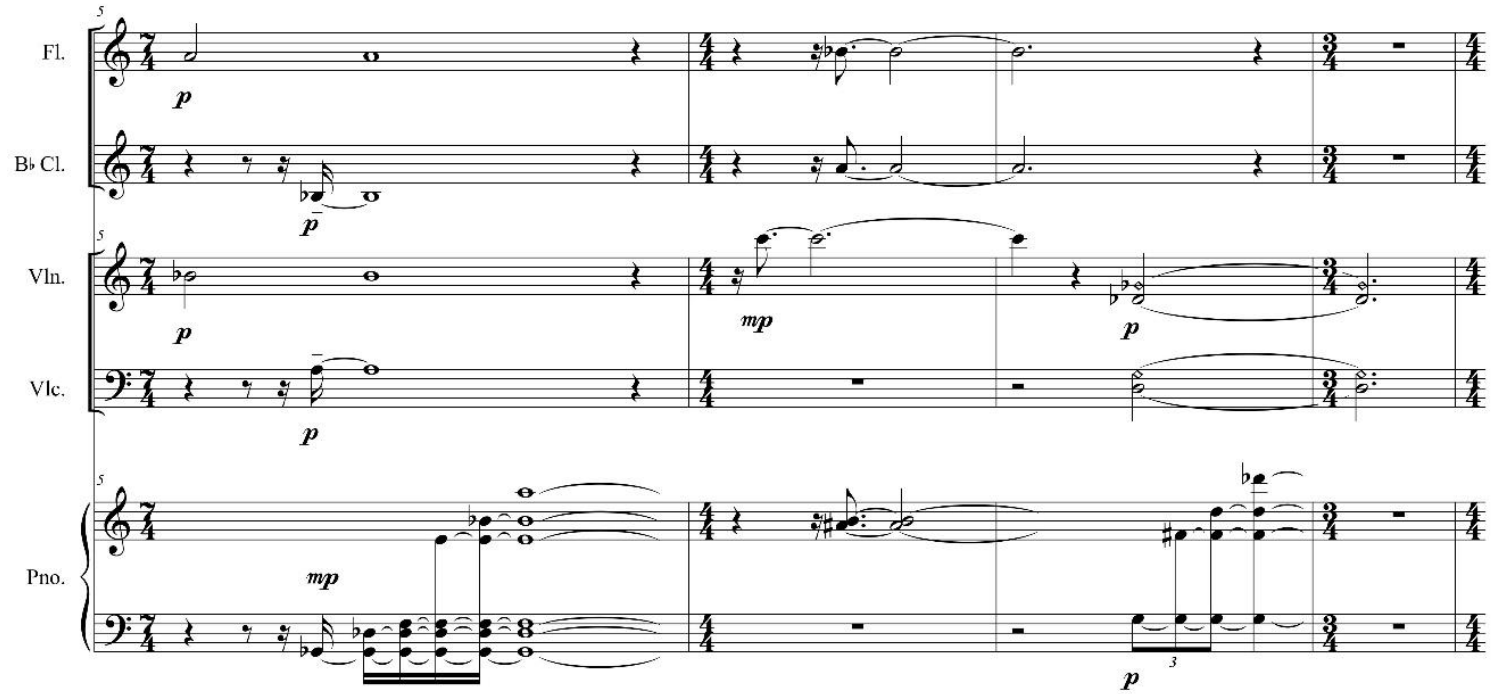

Figure 11: First section of Oito Momentos para Pierrot Ensemble.

\section{4 - Compositional Planning of Plate One Nix}

The title for this piece comes from an anagram of the word "exponential", which is related to the probability function that lies in the core of the computer application used to generate the material for the piece, i.e., the number of sections with their specific durations and, also, the internal events (harmonic profile) with their durations. The initial idea was to plan a short piece for string quartet. Therefore, the maximum number of simultaneous pitch-classes was fixed in 8 . Also, instead of thinking in terms of seconds, the durations generated by the 
system were associated with rhythmic values expressed in standard traditional notation. These values were quantized in order to be properly notated. The quarter note was used as the unit of reference.

For the planning of Plate One Nix, the system was fed with the following values: 1) $d t=120,2) m s=10$, 3) $\max =8$, 4) $\min =1,5) k=20$, and 6) the twelvetone series derived from Messiaen's fifth mode of limited transposition (0 1267 834591011 ); Table 3 shows the eleven sections of the work with their respective durations in seconds; and Table 4 shows the events and the durations for the first section. Figure 12 shows the quantization methodology used for the first section of the work, which is shown in Figure 13.

Table 3: Duration of the eight sections of Plate One Nix.

\begin{tabular}{cc}
\hline \hline Section Duration(quarter notes) \\
\hline 1 & 28.03 \\
2 & 22.48 \\
3 & 14.64 \\
4 & 15.11 \\
5 & 11.83 \\
6 & 4.47 \\
7 & 4.26 \\
8 & 22.06 \\
9 & 0.61 \\
10 & 17.18 \\
11 & 20.53 \\
\hline \hline
\end{tabular}

Table 4: Events and their durations for the first section of Plate One Nix.

\begin{tabular}{cc}
\hline \hline Event & Duration(quarter notes) \\
\hline $\mathrm{A} b, \mathrm{~A}, \mathrm{~B} b, \mathrm{D}$ & 2.66 \\
$\mathrm{D}, \mathrm{Eb}, \mathrm{E} \mathrm{A}, \mathrm{A}, \mathrm{Bb}$ & 0.22 \\
$\mathrm{~A}, \mathrm{D}, \mathrm{Eb}, \mathrm{E}, \mathrm{B} b$ & 9.25 \\
$\mathrm{~A} b, \mathrm{D}, \mathrm{F} \sharp, \mathrm{G}$ & 9.58 \\
$\mathrm{E} b, \mathrm{E}, \mathrm{F}, \mathrm{D}$ ), D & 7.04 \\
$\mathrm{C}, \mathrm{D} b$ & 0.01 \\
$\mathrm{C}, \mathrm{D} b, \mathrm{D}, \mathrm{F} \sharp, \mathrm{G}, \mathrm{Ab}$ & 6.31 \\
\hline \hline
\end{tabular}




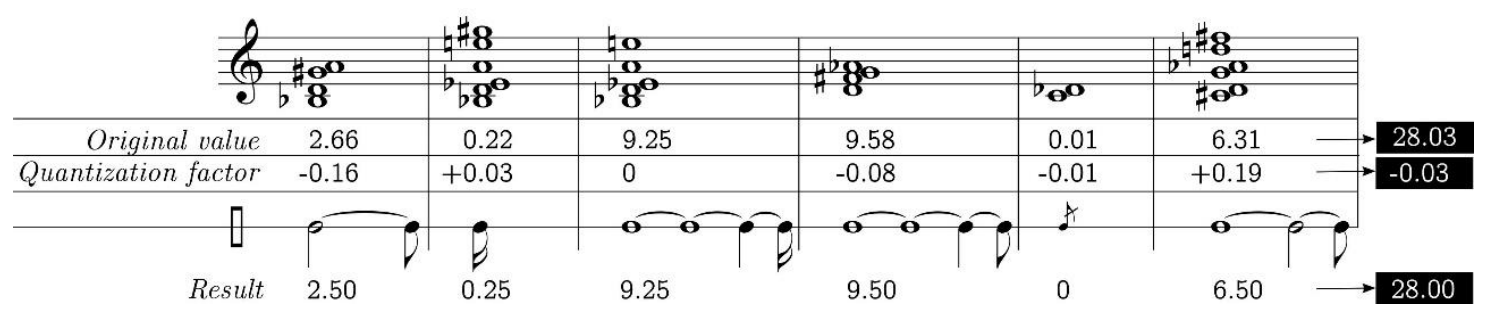

Figure 12: Quantization methodology for the first section of Plate One Nix.

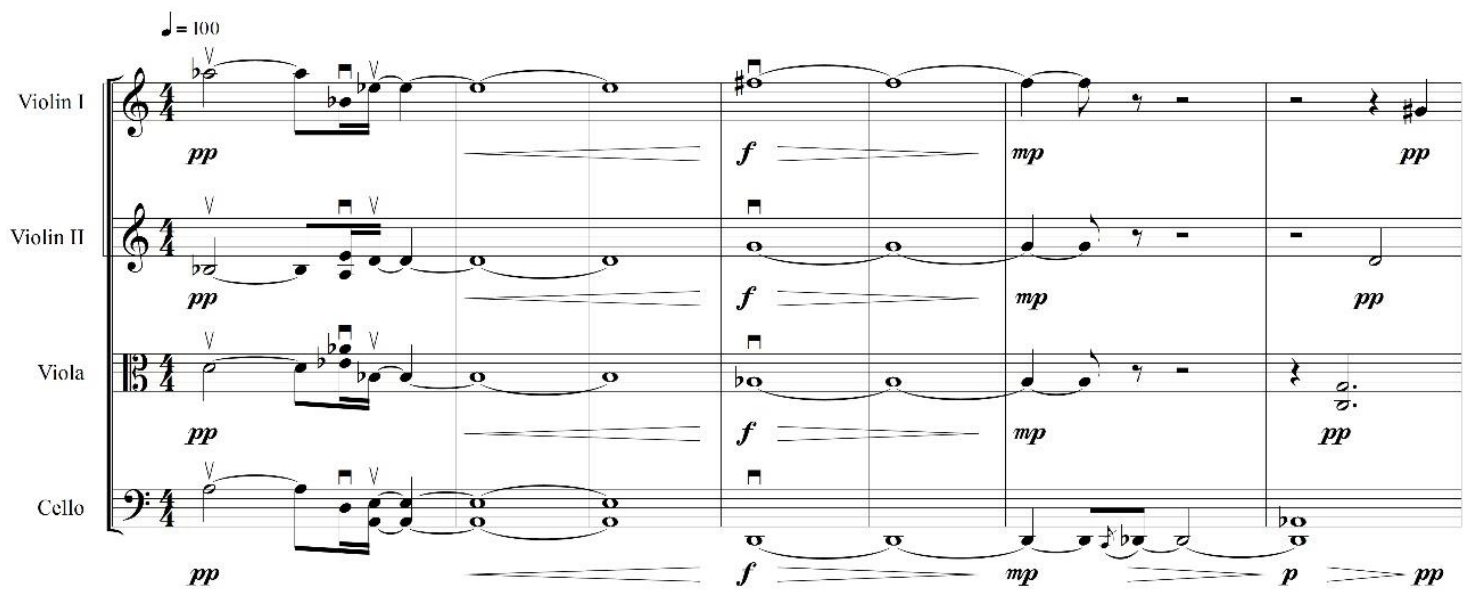

Figure 13: First section of Plate One Nix.

\section{5 - Conclusions}

In this article, we have shown how the compositional planning of Oito Momentos para Pierrot Ensemble and Plate One Nix was made possible by the use of stochastic procedures in order to produce a structure of sections and harmonic events. Thus, empirical compositional procedures applied to surface parameters such as rhythm, contour, articulation, tempo, and dynamics were integrated with more rational procedures by the use of probabilistic distributions. It is important to notice that an intuition about the intrinsic characteristics of probabilistic distributions has been fundamental to foreshadow the behavior of events and their structural interrelations. In addition, the development of a tool that makes transparent the mathematical operations to other composers facilitates the access of the stochastic techniques employed here, once they became more generic and viable to be applied in different stylistic contexts. 


\section{References}

1. Bernard, Jonathan W. 1987. Audible Music: Ligeti's Problem, and His Solution. Music Analysis, V.6, N.3, p.207-236

2. Grisey, Gérard. 1987. Tempus ex Machina: a Composer's Reflection on Musical Time. Contemporary Music Review, vol.2, p.239-275.

3. Papoulis, Athanasios, Pillai, S Unnikrishna. 2002. Probability, Random Variables and Stochastic Process. 4a. Ed. London: McGraw-Hill.

4. Rossetti, Danilo. 2010. Elementos da Música Estocástica em Achorripsis de Iannis Xenakis. In: Anais do XX Congresso da ANPPOM. Florianópolis: ANPPOM, p. $94-100$.

5. Webern, Anton. Variationen fur Klavier. Partitura. Wien: Universal, 1965.

6. Xenakis, Iannis. 1992. Formalized Music: Thought and Mathematics in Music. Hillsdale, NY: Pendragon Press.

7. 1994. Kéleütha: Écrits. Paris: L'Arche. 